ten nearest the stove had given way to putrefaction. Three of the rows most distant from the stove had yielded, while here and there over the tray particular tubes were singled out and smitten by the infection. Of the whole tray of one hundred tubes, twenty-seven were either muddy or cloudy on the Irth. Thus, doubtless, in a contagious atmosphere, are individuals successively struck down. On the rath all the tubes had given way, but the differences in their contents were extraordinary. All of them contained Bacteria, some few, others in swarms. In some tubes they were slow and sickly in their motions, in some apparently dead, while in others they darted about with rampant vigour. These differences are to be referred to changes in the germinal matter, for the same infusion was presented everywhere to the air. Here also we have a picture of what occurs during an epidemic, the difference in number and energy of the Bacterial swarms resembling the varying intensity of the disease. It becomes obvious from these experiments that of two individuals of the same population, exposed to a contagious atmosphere, the one may be severely, the other lightly attacked, though the two individuals may be as identical as regards susceptibility as two samples of one and the same mutton infusion.

The author traces still further the parallelism of these actions with the progress of infectious disease. The Times of January 17 contained a remarkable letter on Typhoid Fever signed "M.D.," in which occurs the following remarkable statement:- "In one part of it (Edinburgh), congregated together and inhabited by the lowest of the population, there are, according to the Corporation return for 1874 , no less than 14,319 houses or dwellingsmany under one roof, on the 'flat' system-in which there are no house connections whatever with the street sewers, and, consequently, no water-closets. To this day, therefore, all the excrementitious and other refuse of the inhabitants is collected in pails or pans, and remains in their midst, generally in a partitioned-off corner of the living room, until the next day, when it is taken down to the streets and emptied into the Corporation carts. Drumken and vicious though the population be, herded together like sheep, and with the filth collected and kept for twenty-four hours in their very midst, it is a remarkable fact that typhoid fever and diphtheria are simply unknown in these wretched hovels."

This case has its analogue in the following experiment, which is representative of a class. On Nov. 30 a quantity of animal refuse, embracing beef, fish, rabbit, hare, was placed in two large test-tubes opening into a protecting chamber containing six tubes. On Dec. 13, when the refuse was in a state of noisome putrefaction, infusions of whiting, turnip, beef, and mutton were placed in the other four tubes. They were boiled and abandoned to the action of the foul "sewer gas" emitted by their two putrid companions. On Christmas-day the four infusions were limpid. The end of the pipette was then dipped into one of the putrid tubes, and a quantity of matter comparable in smallness to the pock-lymph held on the point of a lancet was transferred to the turnip. Its clearness was not sensibly affected at the time; but on the 26 th it was turbid throughout. On the 27 th a speck from the infected turnip was transferred to the whiting; on the 28 th disease had taken entire possession of the whiting. To the present hour the beef and mutton tubes remain as limpid as distilled water. Just as in the case of the living men and women in Edinburgh, no amount of fetid gas had the power of propagating the plague, as long as the organisms which constitute the true contagium did not gain access to the infusions.

The universal prevalence of the germinal matter of Bacleric in water has been demonstrated with the utmost evidence by the experiments of Dr. Burdon Sanderson. But the germs in water are in a very different condition, as regards readiness for development, from those in air. In water they are thoroughly wetted, and ready, under the proper conditions, to pass rapidly into the finished organism. In air they are more or less desiccated, and require a period of preparation more or less long to bring them up to the starting-point of the water-germs. The rapidity of development in an infusion infected by either a speck of liquid containing Bacteria or a drop of water is extraordinary. On Jan. 4 a thread of glass almost as fine as a hair was dipped into a cloudy turnip infusion, and the tip only of the glass fibre was introduced into a large test-tube containing an infusion of red mullet. Twelve hours subsequently the perfectly pellucid liquid was cloudy throughout. A second test-tube containing the same infusion was infected with a single drop of the distilled water furnished by Messrs. Hopkin and Williams; twelve hours also sufficed to cloud the infusion thus treated. Precisely the same experiments were made with herring with the same result. At this season of the year several days' exposure to the air are needed to produce so great an effect. On Dec. $3^{1}$ a strong turnip-infusion was prepared by digesting thin slices in distilled water at a temperature of $120^{\circ} \mathrm{F}$. The infusion was divided between four large test-tubes, in one of which it was left unboiled, in another boiled for five minutes, in the two remaining ones boiled, and after cooling infected with one drop of beef-infusion containing Bacteria. In twenty-four hours the unboiled tube and the two infected ones were cloudy, the unboiled tube being the most turbid of the three. The infusion here was peculiarly limpid after digestion; for turnip it was quite exceptional, and no amount of searching with the microscope could reveal in it at first the trace of a living Bacterium ; still germs were there which, suitably nourished, passed in a single day into Bacterial swarms without number. Five days have not sufficed to produce an effect approximately equal to this in the boiled tube, which was uninfected but exposed to the common laboratory air.

There cannot, moreover, be a doubt that the germs in the air differ widely among themselves as regards preparedness for development. Some are fresh, others old; some are dry, other's moist. Infected by such germs the same infusion would require different lengths of time to develop Bacterial life. This remark applies to and explains the different degrees of rapidity with which epidemic disease acts upon different people. In some the hatching-period, if it may be called such, is long, in some short, the differences depending upon the different degrees of preparedness of the contagium.

The author refers with particular satisfaction to the untiring patience, the admirable mechanical skill, the veracity in thought, word, and deed displayed throughout this first section of a large and complicated inquiry by his assistant, Mr. John Cottrell, who was zealously aided by his junior: colleague, Mr. Frank Valter.

NOTE. Fan. 3r.-.The notion that the himself to temperatures of $60^{\circ}$ and $70^{\circ} \mathrm{Fahr}$. is an entire misconception. But more of this anon.

THE OCCURRENCE AND MANUFACTURE OF FLINT SKIN-SCRAPERS FROM NEW FER. $S E Y, U . S . A$.

A RMARKABLE feature of the common Indian $A$ relics found in Central New Jersey is the very grea abundance of "skin-scrapers," as one form of stone implements is everywhere known; and the great care that has evidently been bestowed upon them in the making equally attracts the attention when a series of these implements is examined. That a flint implement used in the preparation of slins for clothing and tent-covering should require as much care in its manufacture as an. arrow-point, does not seem probable, and one would naturally expect to find in a scraper simply a comparatively 
dull rubbing edge given to a conveniently sized pebble. Such, however, is seldom or never the case, and the class of implements, to which is given the above name, are as marked in their several peculiarities as is any form of stone implement with which we are familiar.

Having remarked the great abundance of these relics, I desire here more particularly to notice several specimens which are of more than ordinary interest. The illustrations $I, 2,3$, and 4 , are figures of the very smallest scrapers that I have seen; and what is more remarkable than their small size is the beauty of their finish and their symmetry. They are made of differently coloured jasper, were not found together or in the same neighbourhood, showing that they had different origins, and are not ex-

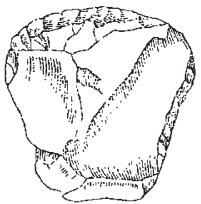

FIG. I.

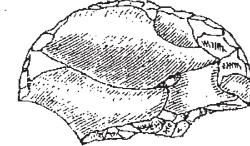

FIG 2. amples of the fancy of some eccentric chipper of flint implements, such as sometimes occur in masses of broken specimens and flakes that indicate the former site of an arrow-maker's labours.

Not one of these four small scrapers appears to be simply a flake, originally of this shape and subsequently chipped at the scraping edge; but the entire surfaces have undoubtedly been carefully wrought, and show that a small mass of the mineral has been worked to the shape and finish of the specimens, as now found. A quite common form of scraper is the base of an arrow or spear point which has been utilised by subsequently chipping the fractured end, so as to give it a bevelled edge; but the specimens here figured cannot be classed with these, inasmuch as there is nothing suggestive of the arrowpoint in their present shape, and unlike them, these four specimens have the under side smooth and slightly concave, a feature not found in the "made over" arrowheads.

Having seen that so much care was expended on these small scrapers, it is quite certain that these implements were put to some important use, but exactly what, it is difficult to determine. Certainly, in the dressing of the skins of our larger mammals they could be of no use, and of but little even when the skins of the smallest, such as squirrels, were used, which was probably seldom the case, as the ilarger quadrupeds were as easily obtained. The

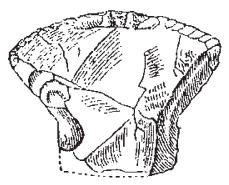

FIG. 3 .

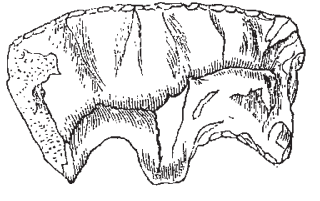

FIG. 4. skins of birds, if used as ornaments, would not need scraping to make them pliable; and I can only suggest that from the fact of having found traces of bone beads, in graves, made from sections of the long bones of wading birds, I have thought it probable that these small scrapers were used in rounding off the ends of such bone beads; and they might also have been used in the shaping and sharpening of the beautiful bone fish-hooks our aborigines were accustomed to make. Such uses would, of course, make the name "skin-scraper" inappropriate, as I am quite disposed to think it is.

Fig. 5 represents a very perfect specimen of the spoonshaped scrapers, such as are common in Europe, and by no means rare in the United States. Those found here, as a rule, are not so symmetrical as the specimen figured, and do not have the "bowl" or concave portion of the spoon so decidedly marked. Our New Jersey specimens have this under-surface generally plain, or but slightly concave; and uniform with the stem or handle of the implement. In the specimen figured this is not the case, and the spoon-shape is so pronounced as to suggest that it is a veritable spoon.

Fig. 5 has been chipped from a very pretty agate pebble, such as occur in the gravelly bed of the upper waters of the Delaware River; and it is an interesting

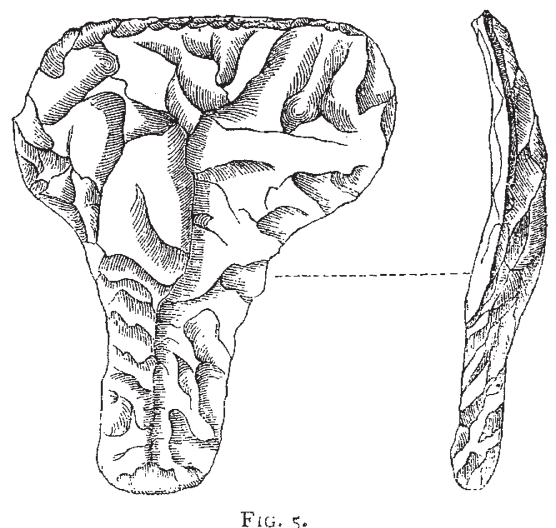

fact connected with this class of relics, that the majority are made of jasper, agate, and quartz, minerals the most difficult to shape, and certainly no better adapted to the ordinary uses of these implements-that of scraping the fat from skins.

One word in conclusion. Mr. C. C. Jones, jun., in his work on the "Antiquities of the Southern Indians," writes, under the head of "Scrapers" that "the spoon-shaped scraper of France and Switzerland is more pronounced in form and purpose than any implement of like character it has been my good fortune to find among the relics of the southern tribes."

It is curious that so much variation in the forms of their stone implements should exist in tribes nearly related, and but a few hundred miles apart. Judging from the specimens figured by the author quoted, scrapers were quite simple in their shape and finish; which, as we have seen, is the opposite of what we find in New Jersey, where as great a variety in shapes and sizes occur as exist in the various patterns of arrow-points. *

Trenton, New Jersey

Charles C. ABbot't

\section{THE RECENT BUTTER CASE}

$\triangle \mathrm{S}$ the case in connection with the Adulteration Act which we discussed in a leading article last week is of considerable importance, both from a scientific and a public point of view, we think it well to put the facts before our readers.

The following summary of the analytical results detailed in Court by the different chemists has been supplied us from a verbatim report of the proceedings before the magistrate at Southwark Police Court.

These results were given after the magistrate's decision had been delivered. They were entirely informal, and took the shape of a discussion, in which everyone appeared to act as his own counsel, and no attempt was made to establish or trace the identity of the samples.

* As authority for applying the term "scraper" to implements similar to Fig. 5, permit me to quote the late Prof. Jeffries Wyman ("Fifth Annual Report of Peabody Museum," 1872, P. 27). He writes, "The term scraper is applied to some of the implements just referred to (a collection from the author), because of their close resemblance to such as bear the same name from the Danish collections belonging to the Museum. They are characterised by having a circular or semi-circuiar flattened head, with a short projection which might serve as a handle, or for the purpose of attaching one They differ from the Danish implements chiefly in their much smaller size." 